\title{
SI113, a Specific Inhibitor of the Sgk1 Kinase Activity that Counteracts Cancer Cell Proliferation
}

\author{
Lucia D'Antona $^{\mathrm{b}}$ Rosario Amato ${ }^{\mathrm{a}}$ Cristina Talarico ${ }^{\mathrm{b}}$ Francesco Ortuso $^{\mathrm{a}}$ \\ Miranda Mennitia Vincenzo Dattilo ${ }^{a}$ Rodolfo Iuliano ${ }^{b}$ Francesco Gigliottib \\ Anna Artese $^{a}$ Giosuè Costa ${ }^{a}$ Silvia Schenone ${ }^{c}$ Francesca Musumeci $^{c}$ \\ Claudia Abbruzzese Lorenzo Botta $^{\mathrm{d}}$ Francesco Trapasso $^{\mathrm{b}}$ Stefano Alcaro \\ Marco G. Paggie Nicola Perrottia \\ aUniversity "Magna Graecia" of Catanzaro, Dept. of "Scienze della Salute", Catanzaro, bUniversity \\ "Magna Graecia" of Catanzaro, Dept. of "Medicina Sperimentale e Clinica", Catanzaro, 'University \\ of Genova, Dipartimento di Farmacia, Genova, dUniversity of Siena, Dipartimento Farmaco Chimico \\ Tecnologico, Siena, ${ }^{E}$ Experimental Oncology, Regina Elena National Cancer Institute, IRCCS, Rome, Italy
}

\section{Key Words}

SGK1 • Kinase inhibitor $•$ Cancer $•$ Apoptosis $・$ Necrosis $•$ Small molecule

\begin{abstract}
Background/Aims: Published observations on serum and glucocorticoid regulated kinase 1 (Sgk1) knockout murine models and Sgk1-specific RNA silencing in the RKO human colon carcinoma cell line point to this kinase as a central player in colon carcinogenesis and in resistance to taxanes. Methods: By in vitro kinase activity inhibition assays, cell cycle and viability analysis in human cancer model systems, we describe the biologic effects of a recently identified kinase inhibitor, SI113, characterized by a substituted pyrazolo[3,4-d]pyrimidine scaffold, that shows specificity for Sgk1. Results: SI113 was able to inhibit in vitro cell growth in cancer cells derived from tumors with different origins. In RKO cells, this kinase inhibitor blocked insulin-dependent phosphorylation of the Sgk1 substrate Mdm2, the main regulator of p53 protein stability, and induced necrosis and apoptosis when used as a single agent. Finally, SI113 potentiated the effects of paclitaxel on cell viability. Conclusion: Since SI113 appears to be effective in inducing cell death in RKO cells, potentiating paclitaxel sensitivity, we believe that this new molecule could be efficiently employed, alone or in combination with paclitaxel, in colon cancer chemotherapy.
\end{abstract}

Copyright @ 2015 S. Karger AG, Basel

R. Amato, S. Alcaro, M.G. Paggi and N. Perrotti contributed equally and thus share last authorship

Nicola Perrotti

Marco G. Paggi

\section{KARGER 125}

Department of Human Health, University Magna Graecia at Catanzaro

Viale Europa, 88100 Catanzaro (Italy) and Experimental Oncology, Regina Elena National Cancer Institute, IRCCS, Via E. Chianesi, 53, 00144 Rome (Italy)

E-Mail perrotti@unicz.it and E-Mail paggi@ifo.it 


\section{Introduction}

The serum- and glucocorticoid-regulated kinase (Sgk) family consists of three members, Sgk1, Sgk2 and Sgk3, all displaying serine/threonine kinase activity and sharing structural and functional similarities with the Akt family of kinases [1]. Sgk1 was originally described as a key enzyme in the hormonal regulation of sodium absorption by the amiloride-sensitive sodium channel ( $\mathrm{ENaC}$ ) [2]. The activity of $\mathrm{ENaC}$, through Sgk1, is regulated by aldosterone, glucocorticoids, insulin and vasopressin at the transcriptional and post-translational level $[3,4]$.

Sgk1 activity is strictly correlated with its post-translational modifications. It becomes a substrate of the mTOR kinase that phosphorylates its hydrophobic motif (H-motif) at the level of S422. Then, 3-phosphoinositide-dependent kinase-1 (Pdk1) binds to the H-motif of Sgk1, at the level of phospho-S422, and further phosphorylates the protein at T256 [5]. Interestingly, the mTOR inhibitor Torin-1 has been proposed as a powerful drug candidate for the therapy of metastatic colorectal cancer [6].

Sgk1 has been implicated in mediating insulin, IGF1 (Insulin like Growth Factor 1), glucocorticoid and IL2 (Interleukin2)-dependent survival signals in normal and cancer cells [7-11], thus gaining significant attention in the field of molecular oncology. Indeed, the antiapoptotic function of Sgk1 suggests its possible involvement in human carcinogenesis. Sgk1 increased expression has been found in human tumors, like prostate cancer [12] and nonsmall cell lung cancer of the squamous subtype, where Sgk1 mRNA level correlates with several clinical prognostic indicators [13]. Sgk1 knockout mice appear to be resistant to the chemical carcinogens used for the induction of colon cancer [14]. Interestingly, the active Sgk1 kinase regulates cell survival, proliferation and differentiation through Mdm2 (Mouse Double Minute 2), that directs p53 to ubiquitylation and proteosomal degradation [15] and, by modulating the expression of RanBP1 (Ran Binding Protein 1), it affects mitotic stability and paclitaxel sensitivity of RKO colon carcinoma cells in culture [16]. Sgk1 interacts with enzymes involved in the metabolism of glycoproteins and lysophospholipids [17, 18], suggesting a role in the development of some of the metabolic alterations that may affect colorectal cancer progression [19-22]. We recently demonstrated that Sgk1 specific RNA silencing in cultured RKO colon carcinoma cells enhances paclitaxel sensitivity, measured as early and late apoptosis [16].

Taken together, these observations suggest an important role for Sgk1 in carcinogenesis and in the mechanisms responsible for resistance to chemotherapy [23]. Sgk1 may thus be considered an interesting molecular target in the therapy of some human tumors [24; $15,25]$. The expression level of Sgk family of proteins may have a central role in tumors that are resistant to Akt inhibition [26]. Notably Sgk1, as compared with its cognate kinase Akt, is highly regulated by steroids. Glucocorticoid receptor antagonism has been recently proposed as a promising therapy in triple negative breast cancer [27], and Sgk1 inhibition is thus expected to be at least as effective as glucocorticoid receptor antagonism.

We recently screened a family of dual Src/Abl inhibitors characterized by a substituted pyrazolo[3,4-d]pyrimidine scaffold $[28,29]$ for their ability to inhibit Sgk1 and Akt kinase activity, competing with ATP for its binding domain. One of these molecules, compound 3 (henceforth SI113), was particularly effective in inhibiting Sgk1 kinase activity, being much less effective on Akt1 activity, probably because it fits better with the lipophilic area of the ATP binding domain that in Sgk1 is larger than in Akt1 [30]. The structural formula of SI113 is shown in Fig. 1, panel A. We now provide more information on the in vitro specificity of SI113 as a Sgk1 inhibitor, and describe the effects of this compound on the proliferation of some cancer cells and on survival and paclitaxel sensitivity in colon carcinoma cells. The results indicate a conceivable use of this Sgk1 kinase inhibitor in the treatment of colon carcinoma as a single agent or in combination with taxanes. 


\section{Cellular Physiology Cell Physiol Biochem 2015;35:2006-2018

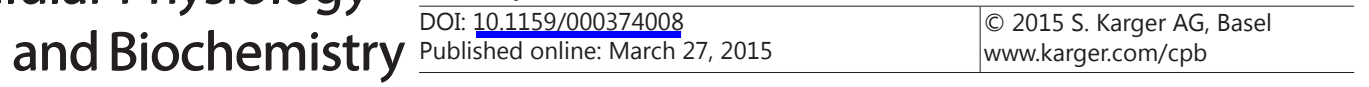 \\ D'Antona et al.: SI113 Inhibits SGK1 in Tumor Cell Lines}

\section{Materials and Methods}

In vitro inhibition of Sgk1 kinase activity by molecules

SI113 was produced and kindly provided by one of us (S.S.). The molecule was first diluted in DMSO as a $50 \mathrm{mM}$ stock solution; then it was further diluted in saline solution at the concentrations indicated in the text. Control cells were treated with vehicle alone.

Active Sgk1, Akt1, Abl, and Src kinases (all by EMD Millipore, Darmstadt, Germany) were incubated in the appropriate kinase buffers provided by the manufacturer in the absence or in the presence of specific target peptides, as indicated in the Results section, according to previously published methods [30]. The reactions were allowed to occur for $30 \mathrm{~min}$ at room temperature, with gentle agitation, prior to adding $10 \mathrm{ml}$ of stopping solution ( $1 \mathrm{mM} \mathrm{ATP}, 2 \%$ bovine serum albumin, $0.6 \% \mathrm{w} / \mathrm{v} \mathrm{HCl}$ ). The reaction mix was clarified by centrifugation in an Eppendorf microcentrifuge at room temperature, for $10 \mathrm{~min}$ at 14,000 rpm. Supernatants $(10 \mu \mathrm{l})$ were applied to a $2.1-\mathrm{cm} \emptyset \mathrm{p} 81$ Whatman paper. Filters were dried, washed with $25 \mathrm{mM}$ phosphoric acid, once with acetone, and then counted in a scintillation counter to measure the radioactivity incorporated in the substrate peptide. Background radioactivity was estimated by measuring the amount of radioactivity incorporated in the absence of the active kinase.

\section{Cell culture and transfection}

RKO colorectal adenocarcinoma cells, MCF-7 breast cancer cells and A-172 glioblastoma multiforme cells were plated at a concentration of $5 \times 10^{5}$ cells $/ \mathrm{ml}$ in $100 \mathrm{~mm} \emptyset$ plates in DMEM-low glucose medium (Life Technologies, Inc., Grand Island, NY) supplemented with 10\% fetal bovine serum and 1\% penicillin/ streptomycin solution (Aurogene, Rome, Italy). Cells were cultured at $37^{\circ} \mathrm{C}$ in a humidified atmosphere of $\mathrm{CO}_{2}(5 \%)$ and air (95\%). After $24 \mathrm{~h}$, when cells were approximately 60\% confluent, SI113 or vehicle was added at the desired concentration for the time indicated in Results section. Paclitaxel was used at a concentration $10 \mathrm{nM}$ for $16 \mathrm{~h}$, alone or in combination with SI113. Cell proliferation was evaluated by measuring the total number of cells using a Burker chamber. Cell viability was monitored by trypan blue exclusion. RKO cells were transfected with an expression plasmid (PcDNA4-TO myc Sgk1)(WT) using Lipofectamine 2000 (Life Technologies, Inc.) following the manufacturer's instructions.

Insulin stimulation and Western blot

Cell cultures were serum-starved for $12 \mathrm{~h}$ before stimulation. $1 \mu \mathrm{M}$ insulin was added $30 \mathrm{~min}$ before lysis [Lysis buffer: 50 mM Tris-HCl, pH 7.4, $0.15 \mathrm{M} \mathrm{NaCl}, 0.5$ \% IGEPAL, 25 mM NaF,1 mM DTT, $1 \mathrm{mM} \mathrm{Na}_{3} \mathrm{VO}_{4}$ plus protease inhibitor cocktail $10 \mathrm{X}$ (Sigma-Aldrich, St. Louis, MO)].

Protein extracts (10-30 $\mu \mathrm{g} /$ well) were separated by 12\% SDS- polyacrylamide gel electrophoresis and blotted on a $0.45 \mu \mathrm{m}$ nitrocellulose membrane (Bio-Rad). Filters were incubated overnight at $4^{\circ} \mathrm{C}$ in blocking buffer (1X TBS, $0.1 \%$ Tween-20 with 5\% w/v nonfat dry milk).

Insulin-stimulated cells were used for western blot detection of phosphorylated Mdm2 (pMdm2) by means of phospho-serine $166 \mathrm{Mdm} 2$ rabbit polyclonal antibody (\#35215 Cell Signaling, Danvers, MA). Total Mdm2 was detected by Mdm2 Rabbit immunoglobulins (\#C1908 Santa Cruz Biotechnology, Inc. Santa Cruz, CA). Primary antibodies (1:800 dilution) were incubated overnight at $4^{\circ} \mathrm{C}$ in $1 \mathrm{X}$ TBS, $0.1 \%$ Tween-20, containing $3 \%$ BSA.

After incubation with peroxidase-linked secondary antibodies, bands were detected by chemiluminescence using the ECK kit (GE Healthcare). When membrane stripping was indicated, filters were incubated for $20 \mathrm{~min}$ at $37^{\circ} \mathrm{C}$ with Restore Western Blot Stripping Buffer (Thermo Scientific, \# 21059).

Inhibition of Sgk1 kinase activity in an intact cell environment

In these experiments, Myc-Sgk1 was immunoprecipitated using a rabbit anti-Myc antibody (Santa Cruz Biotechnology, Inc.), whereas endogenous Sgk1 was immunoprecipitated by means of a Sgk1-specific rabbit polyclonal antibody (\#07-315, EMD Millipore). Immunoprecipitates were employed in the kinase assay reaction as described above, according to previously published methods $[3,15]$.

Apoptosis and Cell cycle assays

Guava Nexin Assay. Apoptosis was studied in adherent RHO cells. To this end, the culture medium was aspirated and discharged, whereas the remaining adherent cells growing in monolayer were washed 


\section{Cellular Physiology Cell Physiol Biochem 2015;35:2006-2018

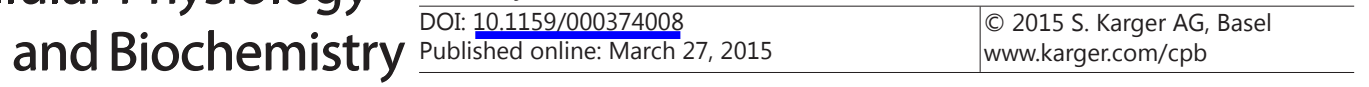

extensively with calcium- and magnesium-free Dulbecco's phosphate buffered saline (PBS). Cells were then trypsinized, diluted with complete culture medium (plus serum) to stop the proteolytic activity, centrifuged, washed with PBS and used for the nexin assay following the instructions of the manufacturer. Briefly, $2 \mathrm{x}$ $10^{5}$ RKO cells, untreated or treated with $12.5 \mu \mathrm{M}$ SI113 for $24 \mathrm{~h}$, were prepared for incubation with $1 \%$ BSA.

$2 \times 10^{4}$ cells were incubated with $100 \mu \mathrm{l}$ Guava Nexin Reagent (100 tests, Lot No. 14-0032, Merck Millipore), a pre-made cocktail containing Annexin V-PE and 7-AAD in buffer, in a $200 \mu$ l final volume. After 20 min incubation at room temperature in the dark, samples were ready to be acquired by the Guava System.

The Guava Nexin Assay utilizes Annexin V-PE to detect phosphatidylserine (PS) on the external membrane of apoptotic cells. The cells impermeant dye, 7-AAD, is also used in the Guava Nexin Assay as an indicator of cell membrane structural integrity. 7-AAD is excluded from live, healthy cells as well as early apoptotic cells.

The assay allows the detection of three populations of cells, i.e.: non-apoptotic cells AnnexinV(-) and 7-AAD(-); early apoptotic cells Annexin $\mathrm{V}(+)$ and 7-AAD(-) and late stage apoptotic and dead cells Annexin $\mathrm{V}(+)$ and 7-AAD $(+)$.

The results include count and percentage of cells in each of the quadrant-defined populations, as well as the mean fluorescence intensity of Annexin $\mathrm{V}$ and 7-AAD for each population.

Guava Cell Cycle Assay. RKO cells $\left(5 \times 10^{4}\right)$ were plated in $65 \mathrm{~mm} \emptyset$ plates and incubated at $37^{\circ} \mathrm{C}$ to allow the cells to attach to the plate and to grow up to $60-80 \%$ confluence before proceeding. RKO cells were treated with $12.5 \mu \mathrm{M}$ SI113 for $24 \mathrm{~h}$ and paclitaxel $10 \mathrm{nM}$ for $16 \mathrm{~h}$. Cells were harvested by trypsinization, fixed in ice-cold $70 \%$ ethanol and stored at $-20^{\circ} \mathrm{C}$ overnight, prior to staining. Cell pellets were washed twice with cold PBS and incubated with $200 \mu \mathrm{l}$ of a propidium iodide-based staining reagent (Guava Cell Cycle Reagent. 4700-0160, Merck Millipore) at room temperature for $30 \mathrm{~min}$. All samples were transferred to 1.5 $\mathrm{ml}$ microcentrifuge tubes and analyzed on the Guava Instrument.

\section{Statistical analysis}

All tests were done at least in triplicates, as indicated, and the results were expressed as mean +/Standard Error (SE). Differences between groups were analyzed by unpaired two tailed $t$ Test (Fig. 1 through 5) and by one-way ANOVA followed by Newman-Keuls post hoc test, using the GraphPad Prism v5.01 software (Fig. 6).

\section{Results}

In vitro kinase activity inhibition by SI113

Sgk1, Akt1, Abl and Src kinase activities were measured as radioactivity incorporated in specific target peptides, i.e.:crosstide (GRPRTSSFAEGKK) for Sgk1 and Akt1, Cdc2 aa 6-20 (KVEKIGEGTYGVVYK) for Src, and ABLtide (EAIYAAPFAKKK) for Abl according to previously published methods $[3,31,32]$, in the presence or absence of $12.5 \mu \mathrm{M}$ SI113 for $30 \mathrm{~min}$. Sgk1 kinase activity was completely abrogated by this compound, whereas variable amounts of residual kinase activity persisted for the other three kinases tested (Table 1). Interestingly, Src kinase activity, at lower SI113 concentration (30 nM), appeared significantly enhanced, possibly representing a consequence of allosteric regulation and/or binding dependent conformational change of this kinase (data not shown).

Table 1. Inhibition of different kinase activities by SI113.Residual activity of the respective kinases after exposure to $12.5 \mu \mathrm{M}$ SI113 for $30 \mathrm{~min}$. Values are the average of three experiments performed in triplicate and are expressed as percent residual kinase activity in the presence of SI113 compared to the respective activity in the presence of the vehicle alone

\begin{tabular}{|c|c|c|}
\hline Kinase full name & Kinase short name & $\%$ residual activity \\
\hline Serum- and glucocorticoid-regulated kinase 1 & Sgk1 & $0 \pm 0$ \\
\hline RAC-alpha serine/threonine-protein kinase & Akt1 & $87 \pm 3.8$ \\
\hline Abelson murine leukemia viral oncogene homolog & Abl & $37 \pm 1.6$ \\
\hline Sarcoma kinase & Src & $40.3 \pm 9.7$ \\
\hline
\end{tabular}




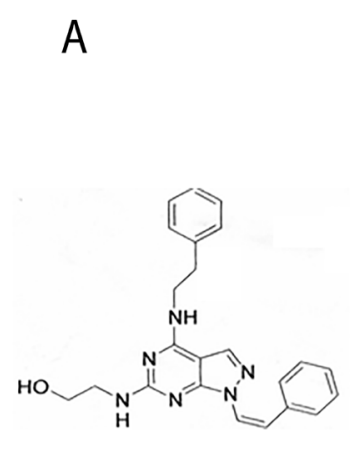

C

RKO Cell viability-Dose response-

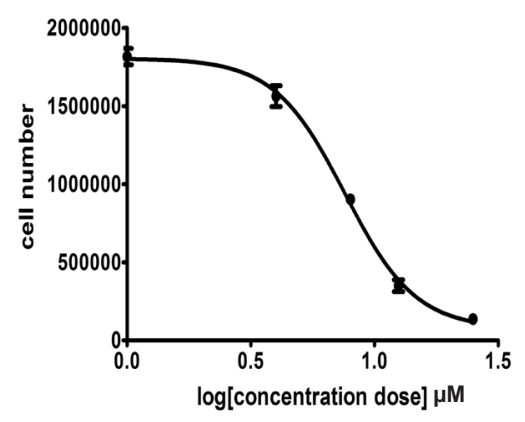

B
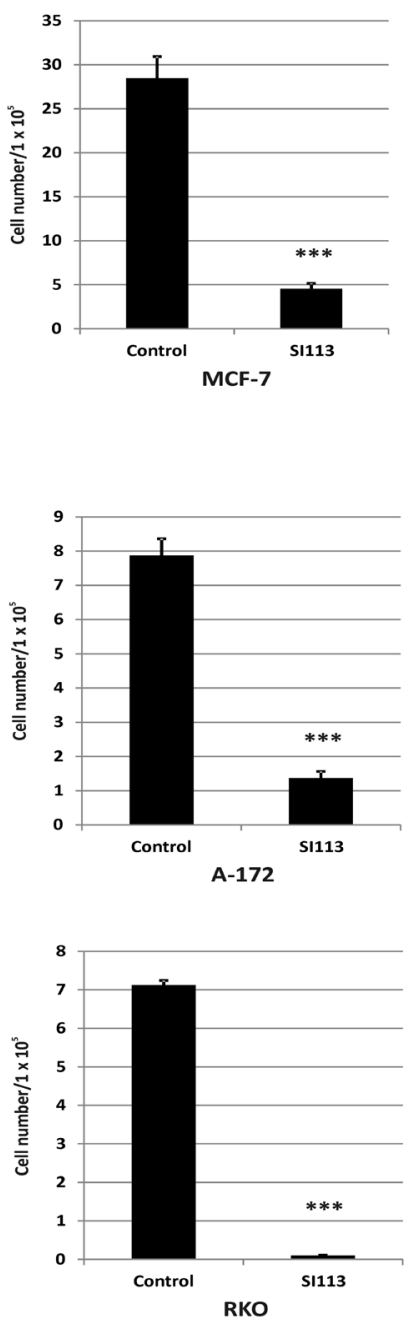

Fig. 1. Growth inhibition induced by SI113 in RKO, MCF-7 and A-172 human cancer in RKO cell lines. A. Structural formula of the SI113 molecule. B. MCF-7 breast cancer cells (top), A-172 glioblastoma multiforme cells (middle) and RKO colon carcinoma cells (bottom). The bar diagrams represent the number of viable cells, untreated or treated with SI113 $(12.5 \mu \mathrm{M})$ for $72 \mathrm{~h}$. Values for treated and untreated cells were compared by unpaired two-tailed Student's $t$ test. Results represent the mean \pm S.E. of three independent experiments for each cell line. Statistical significance: RKO cells $\left(P=4.00452 \times 10^{-7}\right)$, MCF-7 cells $(P=0.00069)$, A-172 cells $(P=0.00024)$. ${ }^{* * *} P \leq 0.001$. C. Dose dependent inhibition of RKO cells proliferation. SI113 concentrations $(1,4,8,12.5$ and $25 \mu \mathrm{M})$ are expressed in log scale. Viable cells were counted after $72 \mathrm{~h}$.

SI113 effect on cell number and viability in RKO, MCF-7 and A-172 human cancer cell lines RKO colorectal adenocarcinoma, MCF-7 breast cancer and A-172 glioblastoma multiforme cell lines were plated as indicated in the Methods section. SI113 (12.5 $\mu \mathrm{M})$ was added for $72 \mathrm{~h}$. Control cells were treated with vehicle alone. Cells were then trypsinized, and viable cells were stained with trypan blue and counted. In all three cell lines, SI113 determined a significant reduction in the number of viable cells (Fig. 1 panel B, MCF-7 (top), A-172 (middle) and RKO cells (bottom). The most notable effect in cell number reduction was achieved in the RKO cell line. A dose/response curve describing the inhibitory effect of SI113 on RKO cells proliferation is shown in Fig. 1 panel C.

SI113 was added at concentration of $1,4,8,12.5$ and $25 \mu \mathrm{M}$. Viable cells were counted after $72 \mathrm{~h}$ as above. Half-maximal inhibitory dose corresponded to approximately $8 \mu \mathrm{M}$. 
Fig. 2. SI113-induced apoptosis in RKO cells. RKO cells were treated with SI113 (12.5 $\mu \mathrm{M})$ for $24 \mathrm{~h}$. The percentage of cells stained with Annexin V (early and late stage apoptotic cells) and 7-AAD (late stage apoptotic and dead cells) was calculated by the Guava Nexin Assay. A. The bar diagrams represent the number of control cells and those treated with SI113 for $24 \mathrm{~h}$ in a parallel experiment. Data represent means +/- S.E. from triplicates $(P=0.0028)$. B. Representative FCM analyses are shown. C. The bar diagrams depict the percentage of cells that are Annexin $\mathrm{V}(+)$ and 7-AAD(-) (early apopotosis) and the percentage of cells that are Annexin $\mathrm{V}(+)$ and 7-AAD $(+)$ (late apoptosis) after exposure to SI113 , as indicated. SI113 treatment for $24 \mathrm{~h}$ determined a significant increase in the percentage of Annexin( + ) cells (early and late apoptosis $(P=0.029)$ and a significant increase in the percentage of Annexin(+) and 7-AAD $(+)$ cells (late apoptosis, $P=0.035$ ). * $P \leq 0.05$; ** $P \leq 0.01$.

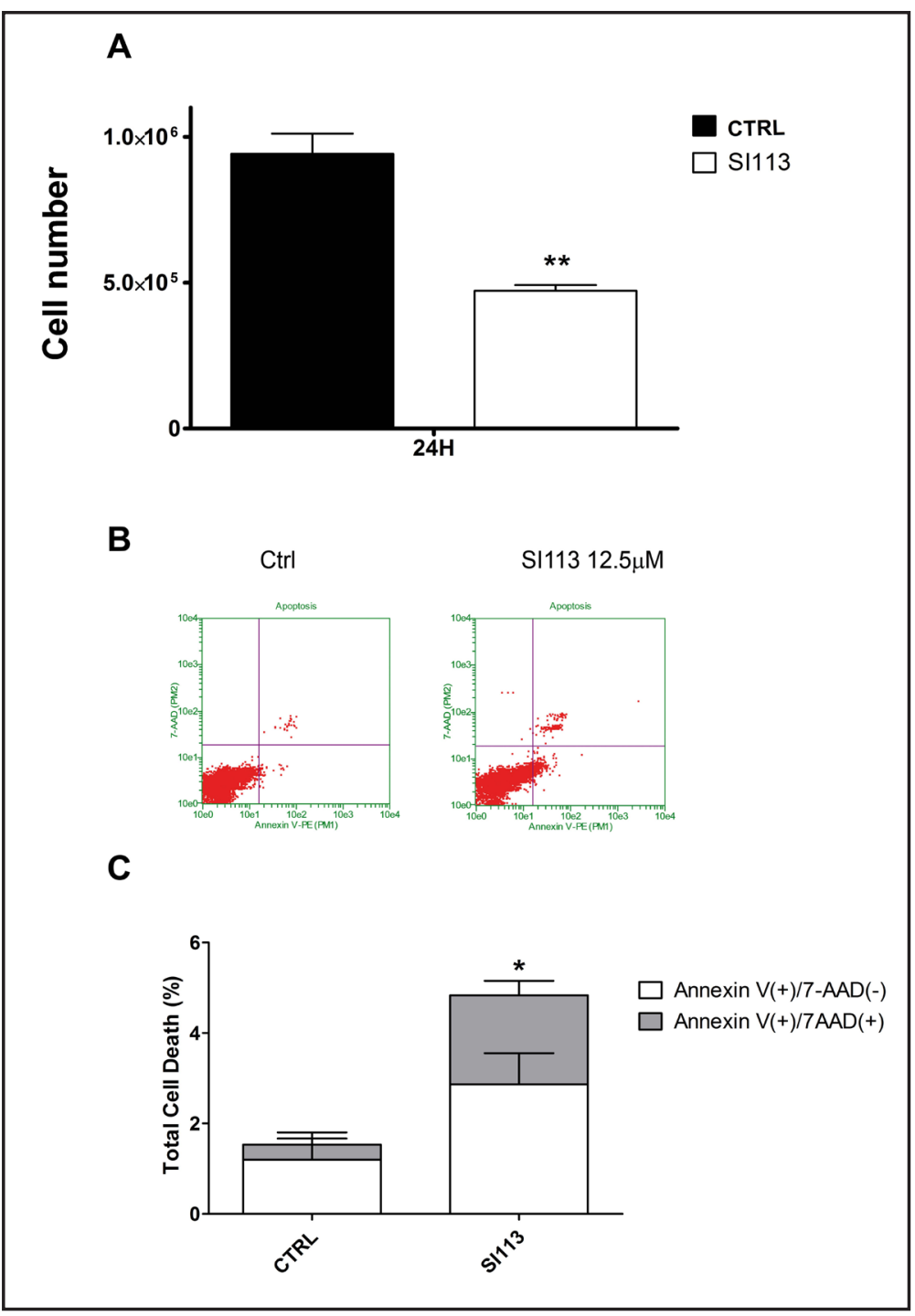

SI113 induces apoptosis in RKO cells

Since several published observations point to a crucial role played by Sgk1 in colon carcinogenesis (see above in the Introduction) we elected to focus on some mechanistic and functional effects of SI113 on the RKO cell line.

Treatment with $12.5 \mu \mathrm{M}$ SI113 for $24 \mathrm{~h}$ induced a significant and important (more than $50 \%$ ) decrease in total cell number (Fig. 2 panel A). We then examined the effects of SI113 $(12.5 \mu \mathrm{M}$ for $24 \mathrm{~h})$ on the induction of apoptosis in RKO cells. We focused on the early and late phases of apoptosis and analyzed the adherent cells only, as specified in the Methods section. Cells were labelled with Annexin-V-Fluorescein and 7-AAD, and the percentage of Annexin(+) cells including Annexin- $V(+) / 7-A A D(-)$ (early apoptotic cells ) and Annexin$\mathrm{V}(+) / 7-\mathrm{AAD}(+)$ (late apoptotic cells) was determined by flow cytofluorometry (Fig. 2, panel $B)$. A significant increase in the percentage of Annexin $V(+)$ cells was recorded $(1.53 \pm 0.57 \%$ for control cells, $4.8 \pm 0.81 \%$ for SI113-treated cells, $P=0.029)$. Interestingly, the percentage of Annexin $\mathrm{V}(+) / 7-\mathrm{AAD}(+)$ (late apoptotic cells) also increased significantly $(0.33 \pm 0.11$ $\%$ for control cells, $1.96 \pm 0.32 \%$ for SI113-treated cells, $P=0.035$ ) (Fig. 2 panel C). The increase in the percentage of apoptotic cells is only apparently small. Since solely adherent cells were analyzed, most of the dead cells were discharged with the medium. The increase in apoptotic cells thus represents the percentage of adherent cells that were actually in the process of dying at that specified time point. 
Fig. 3. Inhibition of isolated Sgk1 kinase activity by SI113. A. Kinase assay was performed after immunoprecipitation of the chimeric protein Myc-Sgk1 previously overexpressed by transfection in RKO colon carcinoma cells. Before lysis and immunoprecipitation, cells were treated with insulin and/or SI113, as specified. Insulin significantly increased Sgk1 activity, as expected, in the absence of SI113 ( $P=0.001)$. SI113 significantly reduced insulin-stimulated Myc-Sgk1 kinase activity $(P=0.017)$. B. Kinase assay was performed after immunoprecipitation of the endogenous Sgk1 protein in RKO colon carcinoma cells. Before lysis and immunoprecipitation, cells were grown in the presence of insulin and/ or SI113, as specified. Again, insulin significantly increased the endogenous Sgk1 activity $\left(P=5.59 \times 10^{-5}\right)$. SI113 significantly reduced basal $(P=0.00023)$ and insulin $(P=0.0027)$ stimulated Sgk1 kinase activity. In both panels, values on the ordinate indicate the counts per minute (c.p.m.) incorporated during the kinase activity in the presence of ${ }^{32} \mathrm{ATP}$. ${ }^{*} P \leq 0.05$; ${ }^{* *} P \leq 0.01$; ${ }^{* * *} P \leq 0.001$.

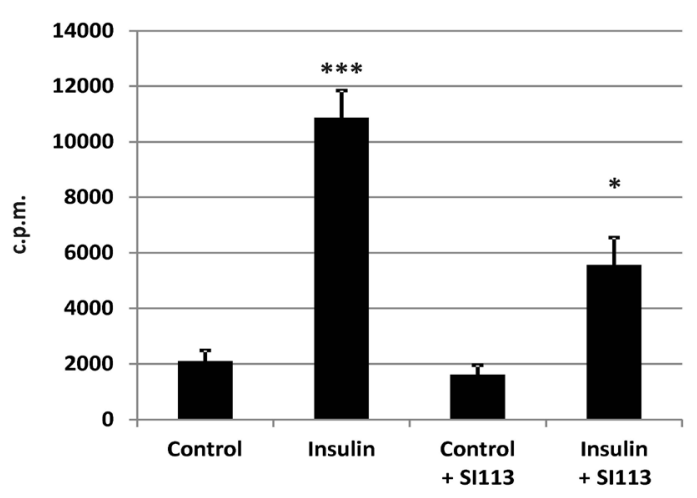

A

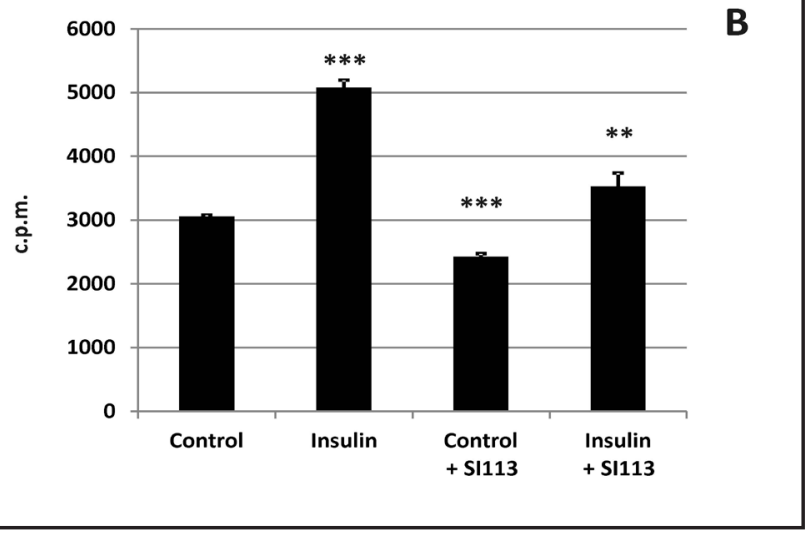

Sgk1 inhibition by SI113 in an intact cellular environment

We investigated the effects of SI113 upon the enzymatic activity of a Myc-tagged Sgk1 molecule. After transiently expressing Myc-tagged Sgk1 in RKO cells, transfected cells were incubated in the presence or absence of $12.5 \mu \mathrm{M} \mathrm{SI} 113$ for $12 \mathrm{~h}$ and/or $10^{-6} \mathrm{M}$ insulin for the following $30 \mathrm{~min}$. Cells were then lysed and the chimeric myc-Sgk1 protein was immunoprecipitated using an anti-Myc antibody. Sgk1 activity was then assayed in the immune complexes. Insulin increased significantly Sgk1 activity, as expected [3]. Incubation of RKO cells in the presence of SI113 led approximately to a 50\% inhibition of insulinstimulated Sgk1 activity, thus suggesting that the molecule was able to permeate the cells and inhibit intracellular Sgk1 activity (Fig. 3, panel A).

Similarly, RKO cells were incubated in the presence or absence of $12.5 \mu \mathrm{M}$ SI113 for 12 $\mathrm{h}$ and $10^{-6} \mathrm{M}$ insulin for the following $30 \mathrm{~min}$. Endogenous Sgk1 activity, immunoprecipitated by a Sgk1 specific antibody, was determined as above. Again, insulin significantly increased the endogenous Sgk1 activity [3]. Cell exposure to SI113 significantly inhibited basal and insulin-stimulated Sgk1-associated kinase activity (Fig. 3, panel B), similarly to what was observed in the experiments with the transfected recombinant kinase.

\section{Effect of SI113 on Mdm2 phosphorylation}

Sgk1 regulates p53 expression through direct phosphorylation on serine 166 and subsequent stabilization of its negative regulator Mdm2 [15]. When RKO cells were incubated in the presence of $12.5 \mu \mathrm{M}$ SI113 for $12 \mathrm{~h}$, basal and insulin-stimulated phosphorylation of Mdm2 on serine 166 was drastically reduced, consistent with the inhibition of Sgk1 activity that is known to phosphorylate and stabilize Mdm2 (Fig. 4, panel A for western blotting and panel B for densitometric evaluation). 
Fig. 4. Inhibition of intracellular Sgk1 kinase activity by SI113. A. RKO colon carcinoma cells were grown in the presence of insulin and/or SI113, as specified. Cells were then lysed and analyzed by Western blot after SDS-PAGE, for the amount of pMdm2, a Sgk1 substrate and a surrogate marker of the Sgk1 kinase activity (upper panel). Loading control was done by determining, after membrane stripping, the amount of the total Mdm2 (phosphorylated and non-phosphorylated) protein (lower panel). MDM2 (approximately $90 \mathrm{kDa}$ ) migrates slight above the $80 \mathrm{kDa}$ marker. Phosphorylation decreased the electrophoretic mobility of the protein, as expected. The figures are representative of three different experiments. B. Bar diagram representation of the Western blot experiments by densitometric analysis and semi-quantitative determination of pMdm2 after normalization against loading control and background. Values (A.U. Mean \pm Standard Error) were obtained in three different experiments. Insulin significant-

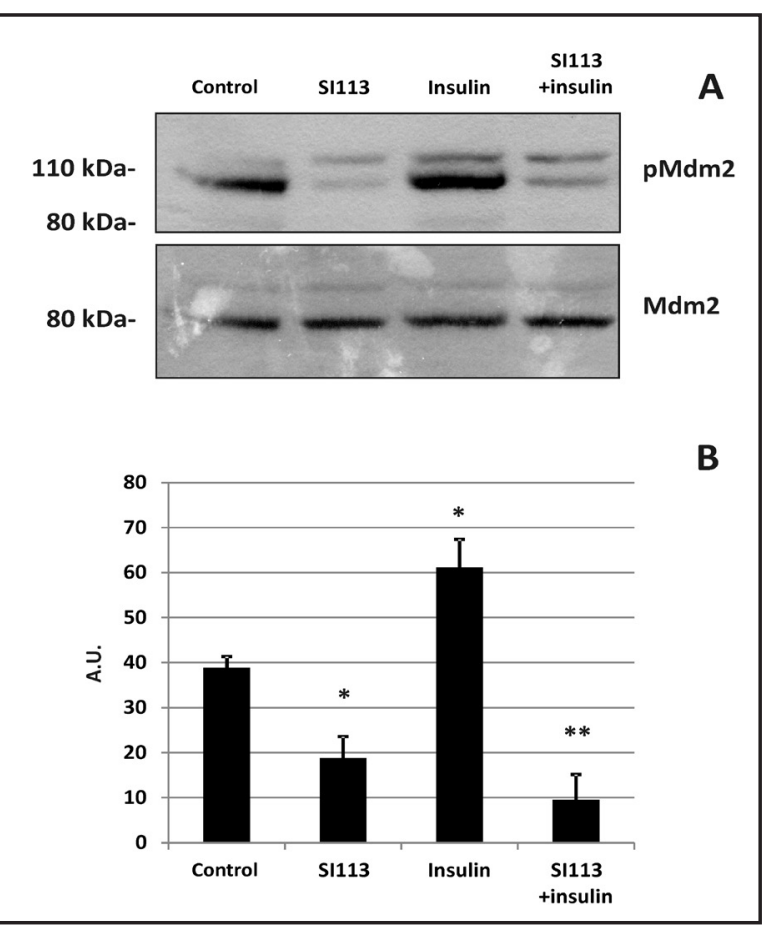
ly increased Sgk1 activity, as expected, in the absence of SI113 $(P=0.027)$. SI113 significantly reduced basal $(P=0.019)$ and insulin-stimulated $(P=0.0033)$ phosphorylation of MDM2. ${ }^{*} P \leq 0.05 ; * * \quad P \leq 0.01$.

Table 2. Cell cycle analysis. Cell cycle distribution in RKO cells treated with $12.5 \mu \mathrm{M}$ SI113 for $24 \mathrm{~h}$ or $10 \mathrm{nM}$ paclitaxel for $16 \mathrm{~h}$. Values are the average of three experiments performed in triplicate and are expressed as percent distribution \pm S. E. ${ }^{* *} \mathrm{P}<0.01 ;{ }^{* * *} \mathrm{P}<0.001$

\begin{tabular}{|c|c|c|c|c|}
\hline & $\% \mathrm{G} 0 / \mathrm{G} 1$ & & $\% \mathrm{G} 2 / \mathrm{M}$ & $\% \mathrm{~S}$ \\
\hline Control & $61.16 \pm 1.28$ & & $25.986 \pm 1.21$ & $11.666 \pm 0.25$ \\
\hline SI113 & $70.036 \pm 1.45$ & $* *$ & $17.686 \pm 1.06$ & $7.153 \pm 0.045$ \\
\hline Paclitaxel & $32.676 \pm 2.35$ & & $53.170 \pm 2.52 * * *$ & $13.603 \pm 0.41$ \\
\hline
\end{tabular}

Cell cycle distribution in RKO cells after SI113 or paclitaxel treatment

In order to analyze the timing of cell cycle progression in the presence of SI113, cell cycle was analyzed by cytofluorometry in cells growing in the presence of serum after staining with propidium iodide. RKO cells treated with $12.5 \mu \mathrm{M}$ SI113 for $24 \mathrm{~h}$ showed a striking delay in cell cycle progression with a significant accumulation in G0-G1, when compared with control cells $(P=0.0024)$ (Table 2$)$. Treatment with $10 \mathrm{nM}$ paclitaxel for 16 h gave quite different results, showing, as expected, a significant increase in the percentage of G2-M cells $(P=0.00019)$ (Table 2), in accordance with the paclitaxel-dependent mitotic arrest [16].

Time course of SI113- and paclitaxel-induced apoptosis and necrosis in RKO cells

RKO cells treated with $12.5 \mu \mathrm{M}$ SI113 and /or $50 \mathrm{nM}$ paclitaxel for 2, 4 or $6 \mathrm{~h}$ were analyzed by cytofluorometry, as indicated above (Fig. 5, panel A, B and C, respectively).

After treatment with SI113, the percentage of late stage apoptotic and dead cells, i.e. Annexin $\mathrm{V}(+)$ and $7-\mathrm{AAD}(+)$, slightly increased at the $4 \mathrm{~h}$ time point of treatment (Fig. 5, panel B), but the difference with control cells reached the statistical significance only at the $6 \mathrm{~h}$ time point $(1.4 \pm 0.4 \%$ for control cells, $2.8 \pm 0.61 \%$ for SI113-treated cells , $P=0.023$ ) (Fig. 5, panel C). Paclitaxel appeared to be more rapidly effective. The percentage of positive 
Fig. 5. Time course of SI113- and paclitaxelinduced apoptosis and necrosis in RKO cells. RKO cells were treated with SI113 (12.5 $\mu \mathrm{M})$ and/or with paclitaxel (50 nM) for 2, 4 and 6 h. The percentage of cells stained with both Annexin $\mathrm{V}$ and 7-AAD (late stage apoptotic cells and dead cells, upper right) was calculated by the Guava Annexin Assay and shown in the representative graphs on the left on each panel. Bar diagrams on the right of each panel depict the percentage of cells undergone apoptosis and necrosis after exposure to the agents, as indicated. To facilitate the interpretation of the data, the full-scale value of the $\mathrm{Y}$ axis is the same for all the right panels. A. After 2 h, RKO cells treated with both
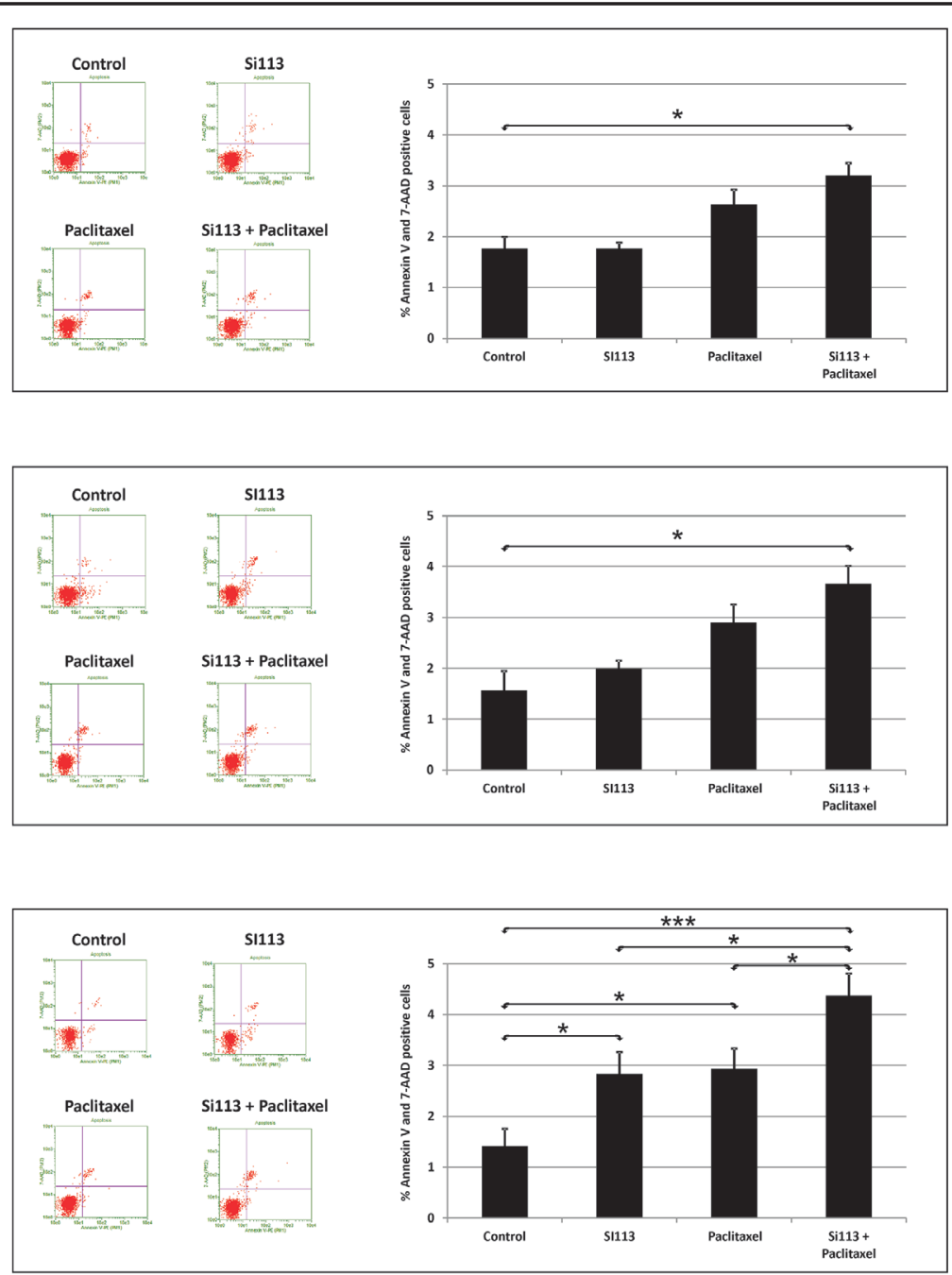
agents demonstrate an increase in the percentage of Annexin $\mathrm{V}(+)$ and 7-AAD $(+)$ cells when compared with control cells $(P=0.014)$, whereas no significant increase was observed with either agents alone. B. After $4 \mathrm{~h}$, RKO cells treated with both agents demonstrate an increase in the percentage of Annexin $\mathrm{V}(+)$ and 7-AAD $(+)$ cells when compared to control cells $(P=0.0158)$, whereas no significant increase was observed with either agents alone. $\mathrm{C}$. After $6 \mathrm{~h}$, the percentage of Annexin $\mathrm{V}(+)$ and 7-AAD $(+)$ cells was significantly increased in cells treated with either SI113 $(P=0.029)$ or paclitaxel $(P=0.013)$ and with the combination of both agents $(P=0.00037)$. The percentage of Annexin $\mathrm{V}(+)$ and 7-AAD $(+)$ cells was significantly higher in cells treated with both agents than the percentage of Annexin $V(+)$ and 7-AAD $(+)$ cells observed after the treatment with either SI113 $(P=0.033)$ or paclitaxel $(P=0.032)$ alone. Data are the average \pm S.E. of six individual values. ${ }^{*} P \leq 0.05$; $^{* * *} P \leq 0.001$.

cells increased at 2 and $4 \mathrm{~h}$ of paclitaxel treatment (Fig. 5, panels A and B, respectively) but, again, the difference with control cells reached significance only at the $6 \mathrm{~h}$ time point $(1.4 \pm$ $0.4 \%$ f or control cells, $2.9 \pm 0.52 \%$ for paclitaxel-treated cells, $P=0.013$ ) (Fig. 5, panel C). Interestingly, the use of both SI113 and paclitaxel significantly increased the percentage of positive cells already at the $2 \mathrm{~h}$ time point $(1.7 \pm 0.23 \%$ for control cells, and $2.9 \pm 0.52 \%$ for paclitaxel-treated cells, $P=0.013$ ) (Fig. 5, panel A). The difference was also significant at the $4 \mathrm{~h}$ time point $(1.4 \pm 0.38 \%$ for control cells and $3.66 \pm 0.35 \%$ for paclitaxel-treated cells, $P=0.0158$ ) (Fig. 5, panel B). After $6 \mathrm{~h}$ of treatment with both agents (Fig. 5, panel $\mathrm{C})$, the percentage of positive cells $(4.36 \pm 0.62)$ was significantly higher than in control samples $(1.4 \pm 0.48 \%, P=0.00037)$, SI113 alone $(2.8 \pm 0.61 \%, P=0.033)$ and paclitaxel 
Fig. 6. SI113 and paclitaxel inhibit RKO cell proliferation. RKO cells were cultured in the absence or presence of SI113, paclitaxel or both, as specified. Cell number and viability was then measured using trypan blue as exclusion dye. The bar diagrams report the number of viable cells. Data are the average \pm S.E. of triplicate experiments and were analyzed by one-way ANOVA followed by Newman Keuls post hoc test $(\mathrm{F}=41.02, P<$ $0.0001)$. SI113 (12.5 $\mu \mathrm{M}$ for $24 \mathrm{~h})$ and paclitaxel (10 nM for $16 \mathrm{~h}$ ), when individually added, significantly reduced the number of

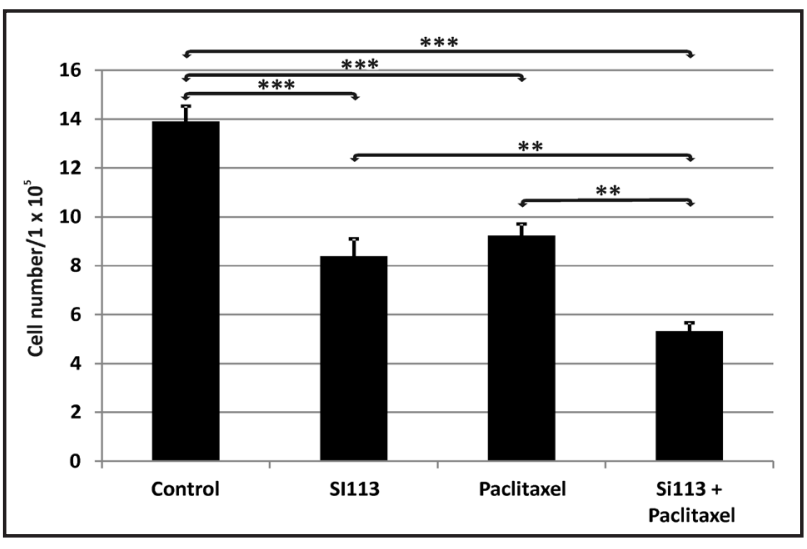
viable cells $(P<0.0001$ and $P<0.0001$, respectively). Treatment with both SI113 and paclitaxel significantly reduced the number of viable cells when compared with control cells $(P<0.0001)$, cells treated with SI113 alone $(P<0.001)$ or paclitaxel alone $(P<0.001)$. ${ }^{* *} P \leq 0.001$; ${ }^{* * *} P \leq 0.0001$.

alone $(2.93 \pm 0.52 \%, P=0.032)$. Taken together, these results strongly suggest that treatment with SI113 can potentiate the effects of paclitaxel on the survival of RKO cells in culture.

\section{SI113 and paclitaxel inhibit RKO cell proliferation}

RKO cell number and viability was measured in control cells and in the presence of 12.5 $\mu \mathrm{M}$ SI113 for $24 \mathrm{~h}, 10 \mathrm{nM}$ paclitaxel for $16 \mathrm{~h}$ or both. Either SI113 or paclitaxel significantly reduced the cell number, as assessed by cell counting in the presence of the trypan blue exclusion dye. The addition of both agents further and significantly reduced cell number and viability (Fig. 6), strongly suggesting that SI113 and paclitaxel may be used together to enhance the effects of either agents alone.

\section{Discussion}

Colorectal carcinoma represents one among the most frequent causes of cancer death. Many epidemiological data support the existence of a link between colon cancer and conditions like obesity, type 2 diabetes, insulin resistance, hyper-insulinemia and insulin therapy [33, 34]. Moreover, enhanced activation and intracellular localization of the insulin receptor appear to play a role in early stages of colon carcinogenesis [35]. The kinase Sgk1, which is activated by insulin, growth factors and steroids, is an interesting candidate to explain the increased cancer risk observed in patients with obesity and insulin resistance, thus representing a potential pharmacological target for these tumors.

The data reported here provide an improved characterization, at a molecular and cellular level, of the SI113 Sgk1 inhibitor previously described by our group [30]. Indeed, this molecule appears effective and selective in inhibiting Sgk1 kinase activity, either evaluating its efficacy using isolated (recombinant or endogenous) proteins in specific kinase assays, or employing Mdm2 as a surrogate marker for Sgk1 kinase activity in an intact cellular environment (RKO cells). Such an inhibitory effect, as expected, influences several major cellular features, enhancing the apoptotic processes, decreasing overall cell viability and, lastly, producing a block in the G1-S transition. All these features appear strictly in accordance with the down-modulation of the signal transduction pathways in which the Sgk1 molecule is actively involved.

Considering the biological role of Sgk1, which can be epitomized as a stress survival factor, associated with the increasing knowledge on the significance of this kinase for cancer cell survival and replication, it is of key importance to make a selective Sgk1 kinase inhibitor available to specifically hit cancer signal transduction pathways and cell survival 
mechanisms. The SI113 molecule, indeed, was effective in vitro in all the cancer cell lines tested so far. Most of our previous studied were carried out on Sgk1 [14-16]. Sgk2 expression appears to be down-regulated in colon cancer [36], whereas Sgk3 expression appears to have a role in the mechanisms of resistance to Akt inhibitors [26]. At present we cannot rule out that some of the effects described for SI113 may be attributed to the inhibition of other of Sgk1-related kinases (namely Sgk2 and Sgk3).

A previous study by our group describes the Sgk1-dependent regulation of RANBP1, a major effector of the RAN GTPase, and the functional consequences of this regulation on microtubule activity and paclitaxel sensitivity in RKO colon adenocarcinoma cells [16]. According to this notion, we detected an obvious cooperation between paclitaxel and SI113 in inhibiting RKO cancer cell growth in vitro.

Given that Sgk1 expression in NSCLC patient samples significantly correlates with cancer malignancy and is thus considered a worse prognostic indicator [13], the in vivo use of a small molecule able to inhibit selectively Sgk1 kinase activity can specifically hit cancer cells, contemporarily sparing normal cells, characterized by a modest expression of the kinase Sgk1. On the other hand, the sometimes ambiguous results described for the clinical use of Akt inhibitors in cancer therapy [37,38], recently attributed to the high expression of Sgk3 [26],can carve out a peculiar role for Sgk inhibitors in blocking the Ras/PI3K/PTEN/ Akt(Sgk)/mTOR pathway in specific neoplastic phenotypes [1].

Interestingly, compounds belonging to the same pyrazolo[3,4-d]pyrimidine library of SI113, showed no apparent sign of toxicity after oral administration for 15 days in mice [39].

The SI113 molecule has a molecular mass $<500 \mathrm{Da}$ [30], and its chemical structure makes it potentially highly available in all body fluids and theoretically able also to cross the blood-brain barrier. Such a feature makes it eligible to perform an exhaustive in vivo analysis of its antineoplastic properties in immunocompromised mice carrying human tumors. In particular, this study suggests the use of SI113 as a pharmacological agent in human colorectal cancer, to be employed alone or in combination with paclitaxel and/or other chemotherapeutic agents.

\section{Acknowledgements}

This work was supported in part by PRIN 2010-2011, prot.2010JCWWKM and PRIN 2010-2011 prot 2010-5YY2HL.R.A. is the recipient of a FIRB BFR12NSCF_003 Young Investigator grant. The authors thank Tania Merlino for English language editing.

\section{Disclosure Statement}

The authors declare no conflict of interest.

\section{References}

1 Bruhn MA, Pearson RB, Hannan RD, Sheppard KE: Second AKT: the rise of SGK in cancer signalling. Growth Factors 2010;28:394-408.

2 Lang F, Cohen P: Regulation and physiological roles of serum- and glucocorticoid-induced protein kinase isoforms. Sci STKE 2001;2001:re17.

-3 Perrotti N, He RA, Phillips SA, Haft CR, Taylor SI: Activation of serum- and glucocorticoid-induced protein kinase (Sgk) by cyclic AMP and insulin. J Biol Chem 2001;276:9406-9412.

- Faletti CJ, Perrotti N, Taylor SI, Blazer-Yost BL: sgk: an essential convergence point for peptide and steroid hormone regulation of ENaC-mediated Na+ transport. Am J Physiol Cell Physiol 2002;282:C494-C500.

-5 Hong F, Larrea MD, Doughty C, Kwiatkowski DJ, Squillace R, Slingerland JM: mTOR-raptor binds and activates SGK1 to regulate p27 phosphorylation. Mol Cell 2008;30:701-711. 


\section{Cellular Physiology Cell Physiol Biochem 2015;35:2006-2018 \begin{tabular}{l|l} 
and $10.1159 / 000374008$ & $\begin{array}{l}\text { D 2015 S. Karger AG, Basel } \\
\text { www.karger.com/cpb }\end{array}$ \\
\hline
\end{tabular}}

6 Francipane MG, Lagasse E: Selective targeting of human colon cancer stem-like cells by the mTOR inhibitor Torin-1. Oncotarget 2013;4:1948-1962.

7 Leong ML, Maiyar AC, Kim B, O'Keeffe BA, Firestone GL: Expression of the serum- and glucocorticoidinducible protein kinase, Sgk, is a cell survival response to multiple types of environmental stress stimuli in mammary epithelial cells. J Biol Chem 2003;278:5871-5882.

8 Mikosz CA, Brickley DR, Sharkey MS, Moran TW, Conzen SD: Glucocorticoid receptor-mediated protection from apoptosis is associated with induction of the serine/threonine survival kinase gene, sgk-1. J Biol Chem 2001;276:16649-16654.

-9 Wu W, Chaudhuri S, Brickley DR, Pang D, Karrison T, Conzen SD: Microarray analysis reveals glucocorticoidregulated survival genes that are associated with inhibition of apoptosis in breast epithelial cells. Cancer Res 2004;64:1757-1764.

10 Chung EJ, Sung YK, Farooq M, Kim Y, Im S, Tak WY, Hwang YJ, Kim YI, Han HS, Kim JC, Kim MK: Gene expression profile analysis in human hepatocellular carcinoma by cDNA microarray. Mol Cells 2002;14:382-387.

11 Amato R, Menniti M, Agosti V, Boito R, Costa N, Bond HM, Barbieri V, Tagliaferri P, Venuta S, Perrotti N: IL-2 signals through Sgk1 and inhibits proliferation and apoptosis in kidney cancer cells. J Mol Med 2007;85:707-721.

12 Sherk AB, Frigo DE, Schnackenberg CG, Bray JD, Laping NJ, Trizna W, Hammond M, Patterson JR, Thompson SK, Kazmin D, Norris JD, McDonnell DP: Development of a small-molecule serum- and glucocorticoidregulated kinase- 1 antagonist and its evaluation as a prostate cancer therapeutic. Cancer Res 2008;68:7475-7483.

13 Abbruzzese C, Mattarocci S, Pizzuti L, Mileo AM, Visca P, Antoniani B, Alessandrini G, Facciolo F, Amato R, D'Antona L, Rinaldi M, Felsani A, Perrotti N, Paggi MG: Determination of SGK1 mRNA in non-small cell lung cancer samples underlines high expression in squamous cell carcinomas. J Exp Clin Cancer Res 2012;31:4.

-14 Nasir O, Wang K, Foller M, Gu S, Bhandaru M, Ackermann TF, Boini KM, Mack A, Klingel K, Amato R, Perrotti N, Kuhl D, Behrens J, Stournaras C, Lang F: Relative resistance of SGK1 knockout mice against chemical carcinogenesis. IUBMB Life 2009;61:768-776.

15 Amato R, D'Antona L, Porciatti G, Agosti V, Menniti M, Rinaldo C, Costa N, Bellacchio E, Mattarocci S, Fuiano G, Soddu S, Paggi MG, Lang F, Perrotti N: Sgk1 activates MDM2-dependent p53 degradation and affects cell proliferation, survival, and differentiation. J Mol Med 2009;87:1221-1239.

-16 Amato R, Scumaci D, D'Antona L, Iuliano R, Menniti M, Di SM, Faniello MC, Colao E, Malatesta P, Zingone A, Agosti V, Costanzo FS, Mileo AM, Paggi MG, Lang F, Cuda G, Lavia P, Perrotti N: Sgk1 enhances RANBP1 transcript levels and decreases taxol sensitivity in RKO colon carcinoma cells. Oncogene 2013;32:45724578.

17 Menniti M, Iuliano R, Foller M, Sopjani M, Alesutan I, Mariggio S, Nofziger C, Perri AM, Amato R, Blazer-Yost B, Corda D, Lang F, Perrotti N: 60kDa lysophospholipase, a new Sgk1 molecular partner involved in the regulation of ENaC. Cell Physiol Biochem 2010;26:587-596.

18 Menniti M, Iuliano R, Amato R, Boito R, Corea M, Le PI, Gulletta E, Fuiano G, Perrotti N: Serum and glucocorticoid-regulated kinase Sgk1 inhibits insulin-dependent activation of phosphomannomutase 2 in transfected COS-7 cells. Am J Physiol Cell Physiol 2005;288:C148-C155.

19 Christiansen MN, Chik J, Lee L, Anugraham M, Abrahams JL, Packer NH: Cell surface protein glycosylation in cancer. Proteomics 2014;14:525-546.

20 Holst S, Stavenhagen K, Balog CI, Koeleman CA, McDonnell LM, Mayboroda OA, Verhoeven A, Mesker WE, Tollenaar RA, Deelder AM, Wuhrer M: Investigations on aberrant glycosylation of glycosphingolipids in colorectal cancer tissues using liquid chromatography and matrix-assisted laser desorption time-of-flight mass spectrometry (MALDI-TOF-MS). Mol Cell Proteomics 2013;12:3081-3093.

21 Leve F, Marcondes TG, Bastos LG, Rabello SV, Tanaka MN, Morgado-Diaz JA: Lysophosphatidic acid induces a migratory phenotype through a crosstalk between RhoA-Rock and Src-FAK signalling in colon cancer cells. Eur J Pharmacol 2011;671:7-17.

22 Zhang H, Bialkowska A, Rusovici R, Chanchevalap S, Shim H, Katz JP, Yang VW, Yun CC: Lysophosphatidic acid facilitates proliferation of colon cancer cells via induction of Kruppel-like factor 5. J Biol Chem 2007;282:15541-15549.

-23 Lang F, Perrotti N, Stournaras C: Colorectal carcinoma cells--regulation of survival and growth by SGK1. Int J Biochem Cell Biol 2010;42:1571-1575. 


\section{Cellular Physiology Cell Physiol Biochem 2015;35:2006-2018 \begin{tabular}{l|l|l}
\hline DOI: 10.1159/000374008 & C 2015 S. Karger AG, Basel
\end{tabular}

24 Lang F, Voelkl J: Therapeutic potential of serum and glucocorticoid inducible kinase inhibition. Expert Opin Investig Drugs 2013;22:701-714.

25 Towhid ST, Liu GL, Ackermann TF, Beier N, Scholz W, Fuchss T, Toulany M, Rodemann HP, Lang F: Inhibition of colonic tumor growth by the selective SGK inhibitor EMD638683. Cell Physiol Biochem 2013;32:838848.

26 Bruhn MA, Pearson RB, Hannan RD, Sheppard KE: AKT-independent PI3-K signaling in cancer - emerging role for SGK3. Cancer Manag Res 2013;5:281-292.

27 Skor MN, Wonder EL, Kocherginsky M, Goyal A, Hall BA, Cai Y, Conzen SD: Glucocorticoid receptor antagonism as a novel therapy for triple-negative breast cancer. Clin Cancer Res 2013;19:6163-6172.

-28 Angelucci A, Schenone S, Gravina GL, Muzi P, Festuccia C, Vicentini C, Botta M, Bologna M: Pyrazolo[3,4-d] pyrimidines c-Src inhibitors reduce epidermal growth factor-induced migration in prostate cancer cells. Eur J Cancer 2006;42:2838-2845.

-29 Radi M, Dreassi E, Brullo C, Crespan E, Tintori C, Bernardo V, Valoti M, Zamperini C, Daigl H, Musumeci F, Carraro F, Naldini A, Filippi I, Maga G, Schenone S, Botta M: Design, synthesis, biological activity, and ADME properties of pyrazolo[3,4-d]pyrimidines active in hypoxic human leukemia cells: a lead optimization study. J Med Chem 2011;54:2610-2626.

- 30 Ortuso F, Amato R, Artese A, D'Antona L, Costa G, Talarico C, Gigliotti F, Bianco C, Trapasso F, Schenone S, Musumeci F, Botta L, Perrotti N, Alcaro S: In Silico Identification and Biological Evaluation of Novel Selective Serum/Glucocorticoid-Inducible Kinase 1 Inhibitors Based on the Pyrazolo-Pyrimidine Scaffold. J Chem Inf Model 2014.

-31 Perrotti N, Taylor SI, Richert ND, Rapp UR, Pastan IH, Roth J: Immunoprecipitation of insulin receptors from cultured human lymphocytes (IM-9 cells) by antibodies to pp60src. Science 1985;227:761-763.

-32 Perrotti N, Grunberger G, Richert ND, Taylor SI: Immunological similarity between the insulin receptor and the protein encoded by the src oncogene. Endocrinology 1986;118:2349-2354.

-33 Bardou M, Barkun AN, Martel M: Obesity and colorectal cancer. Gut 2013;62:933-947.

- 34 Nagata N, Sakamoto K, Arai T, Niikura R, Shimbo T, Shinozaki M, Aoki T, Kishida Y, Sekine K, Tanaka S, Okubo H, Watanabe K, Sakurai T, Yokoi C, Akiyama J, Yanase M, Noda M, Itoh T, Mizokami M, Uemura $\mathrm{N}$ : Visceral abdominal fat measured by computed tomography is associated with an increased risk of colorectal adenoma. Int J Cancer 2014.

35 Abbruzzese C, Diodoro MG, Sperduti I, Mileo AM, Pattaro G, De SL, Cosimelli M, Perrotti N, Paggi MG: Detection of phosphorylated insulin receptor in colorectal adenoma and adenocarcinoma: implications for prognosis and clinical outcome. J Cell Physiol 2015;230:562-567.

-36 Capra M, Nuciforo PG, Confalonieri S, Quarto M, Bianchi M, Nebuloni M, Boldorini R, Pallotti F, Viale G, Gishizky MI, Draetta GF, Di Fiore PP: Frequent alterations in the expression of Serine/Threonine kinases in Human Cancers . Cancer Res 2006;66:8147-8154.

37 Yap TA, Yan L, Patnaik A, Fearen I, Olmos D, Papadopoulos K, Baird RD, Delgado L, Taylor A, Lupinacci L, Riisnaes R, Pope LL, Heaton SP, Thomas G, Garrett MD, Sullivan DM, de Bono JS, Tolcher AW: First-in-man clinical trial of the oral pan-AKT inhibitor MK-2206 in patients with advanced solid tumors. J Clin Oncol 2011;29:4688-4695.

- 38 Konopleva MY, Walter RB, Faderl SH, Jabbour EJ, Zeng Z, Borthakur G, Huang X, Kadia TM, Ruvolo PP, Feliu JB, Lu H, Debose L, Burger JA, Andreeff M, Liu W, Baggerly KA, Kornblau SM, Doyle LA, Estey EH, Kantarjian HM: Preclinical and early clinical evaluation of the oral AKT inhibitor, MK-2206, for the treatment of acute myelogenous leukemia. Clin Cancer Res 2014;20:2226-2235

-39 Manetti F, Santucci A, Locatelli GA, Maga G, Spreafico A, Serchi T, Orlandini M, Bernardini G, Caradonna NP, Spallarossa A, Brullo C, Schenone S, Bruno O, Ranise A, Bondavalli F, Hoffmann O, Bologna M, Angelucci A, Botta M: Identification of a novel pyrazolo[3,4-d]pyrimidine able to inhibit cell proliferation of a human osteogenic sarcoma in vitro and in a xenograft model in mice. J Med Chem 2007;50:5579-5588. 